\title{
OBTENÇÃO E CARACTERIZAÇÃO DE IOGURTE EM PÓ DE LEITE DE OVELHA
}

\author{
E. de ABREU ${ }^{1}$, J. STEFFENS ${ }^{1}$, C. STEFFENS ${ }^{1}$ e A. M. DAHMER ${ }^{1}$
}

${ }^{1}$ Universidade Regional Integrada do Alto Uruguai e das Missões - URI - Campus Erechim.

E-mail para contato: elisangela-abreu@hotmail.com

\begin{abstract}
RESUMO - A busca do consumidor por alimentos saudáveis e diferenciados tem despertado o interesse e incentivado a constante atualização dos profissionais que atuam na pesquisa e desenvolvimento de novos produtos. O leite de ovelha apresenta-se como um alimento com alto teor de sólidos totais, dentre eles proteína e cálcio. A produção de derivados de leite de ovelha ainda é escassa, nesse sentido, com o intuito de expandir o mercado e a gama de produtos derivados desta matéria prima, o objetivo deste trabalho foi desenvolver iogurte em pó de leite de ovelha. Para tanto foi elaborado iogurte natural e submetido à desidratação por meio de liofilização. Observou-se que as características físicoquímicas (proteína, lipídios, lactose, cinzas, acidez e $\mathrm{pH}$ ) do iogurte de leite de ovelha e do iogurte em pó de leite de ovelha foram mantidas. A contagem de bactérias láticas manteve-se em $10^{7} \mathrm{UFC} / \mathrm{g}$, demonstrando, assim, que o processo de liofilização pode ser aplicado na desidratação de iogurte de leite de ovelha, sem alterar as caraterísticas físico-químicas e microbiológicas do produto.
\end{abstract}

\section{INTRODUÇÃO}

Os consumidores estão gradativamente modificando os padrões de consumo, uma vez que, as famílias estão diminuindo, a população está envelhecendo, o acesso facilitado à informação e o aumento da escolaridade, são fatores que estimulam e desafiam os setores de pesquisa, desenvolvimento e inovação das indústrias de alimentos.

Nos produtos lácteos, além do leite de vaca, outros leites apresentam-se como grandes potenciais de produção de novos produtos, como no caso o leite de ovelha que contém $40 \%$ a mais de proteína, altos teores de cálcio, ferro e zinco, e todos os aminoácidos essenciais. Entre os derivados, o iogurte é um dos mais populares devido à sua aceitabilidade bem como as suas propriedades nutricionais e os efeitos potencialmente benéficos para a saúde (Martínez et al., 2012).

Para conservar e ampliar a vida de prateleira do iogurte, uma alternativa é a aplicação do processo de liofilização, transformando-o em pó. Por meio desse processo reduz-se a atividade de água, mantendo-se a qualidade original dos nutrientes. Neste sentido, o presente trabalho teve por objetivo desenvolver e caracterizar o iogurte em pó de leite de ovelha obtido pelo processo de liofilização. 


\section{MATERIAIS E MÉTODOS}

O iogurte de leite de ovelha foi desenvolvido na planta piloto de leite e derivados do SENAI, em Chapecó/SC. Foram utilizados $10 \mathrm{~L}$ de leite de ovelha integral da raça Lacaune, produzido na Cabanha Chapecó. $\mathrm{O}$ leite foi submetido à pasteurização lenta $\left(65^{\circ} \mathrm{C}\right.$ por 30 min) em iogurteira (Mekmilk), com agitação contínua. Em seguida, resfriou-se a $45^{\circ} \mathrm{C}$, com adição de $2 \%$ de fermento lático termofílico Streptococcus salivarius subsp thermophilus e Lactobacillus delbrueckii subsp bulgaricus (CHR-HANSEN), embalou-se em potes plásticos de $2 \mathrm{~L}$, e manteve-se a $45^{\circ} \mathrm{C}$ por 5 horas, em banho maria, até atingir o $\mathrm{pH}$ de 4,6, correspondente ao ponto isoelétrico da caseína, quando se obteve uma coalhada consistente, lisa, uniforme e brilhosa. Posteriormente, resfriou-se a temperatura de $4{ }^{\circ} \mathrm{C}$ e armazenou-se em câmara fria (Sotronic).

Para a fabricação do iogurte em pó de leite de ovelha, utilizou-se o Laboratório da Universidade Regional Integrada - URI em Erechim/RS. Para a realização do processo de liofilização faz-se necessário o congelamento do produto, uma vez que o mesmo consiste na sublimação. Inicialmente, o iogurte de leite de ovelha foi distribuído em uma fina camada de $200 \mathrm{~g}$, em bandejas do liofilizador e submetido ao congelamento em freezer vertical (Consul) a temperatura de $-18{ }^{\circ} \mathrm{C}$ por 24 horas. Em seguida, as bandejas foram retiradas do freezer e introduzidas no liofilizador (Edwars). O processo de liofilização foi conduzido a temperatura de $-40{ }^{\circ} \mathrm{C}$ por 48 horas, posteriormente, o iogurte em pó obtido foi acondicionado em embalagens metálicas com lacre.

O iogurte de leite de ovelha foi caracterizado em relação a umidade, lipídios, proteína, lactose, cinzas, acidez em ácido lático e pH. Enquanto que, para o iogurte em pó de leite de ovelha, além das análises acima citadas, também foi determinada a atividade de água.

Para as análises de umidade, proteína, lactose, acidez em ácido lático e $\mathrm{pH}$ foram utilizadas as metodologias descritas na IN N 68 (Brasil, 2006). A umidade foi determinada pelo método gravimétrico, a proteína pelo método de Kjeldahl, a lactose pelo método titulométrico, seguido de gravimetria, a acidez total por titulação e o $\mathrm{pH}$ pelo método potenciométrico. O teor de lipídios foi determinado conforme metodologia descrita pelo IAL (2008). A atividade de água foi determinada pelo equipamento Aqualab, cujo funcionamento se baseia nos higrômetros de resposta rápida.

Para a caracterização microbiológica do iogurte de leite de ovelha observou-se a RDC $\mathrm{N}^{\mathrm{o}} 12$ (Brasil, 2001) e a IN No 46 (Brasil, 2007), seguindo as análises citadas para leites fermentados, sendo estas: Contagem de Coliformes Totais a $30^{\circ} \mathrm{C}$, Coliformes Termotolerantes a $45^{\circ} \mathrm{C}$, Contagem de Bactérias Láticas, Contagem Bolores e Leveduras e Pesquisa Salmonella.

Para a caracterização do iogurte em pó de leite de ovelha, não há legislação vigente, portanto, foram utilizadas, como referência, as análises citadas na RDC No 12 (Brasil, 2001) para leite em pó, sendo estas, contagem de Coliformes Termotolerantes a $45^{\circ} \mathrm{C}$, contagem de Bolores e Leveduras, contagem de Bacillus cereus, contagem de Staphylococcus aureus, pesquisa de Salmonella, além da contagem de Bactérias Láticas, com o objetivo de verificar a influencia da liofilização na redução das mesmas. 
A Contagem de Coliformes Totais a $30{ }^{\circ} \mathrm{C}$ foi realizada a partir da metodologia ISO 4832:2006. A contagem de Coliformes Termotolerantes a $45^{\circ} \mathrm{C}$ foi realizada segundo metodologia descrita pela IN No 62 (Brasil, 2001). A Contagem de Bactérias Láticas foi realizada a partir da metodologia ISO 7889:2003. A contagem de Bolores e Leveduras foi realizada conforme metodologia descrita pela ISO 6611:2004. A contagem de Bacillus cereus, foi realizada conforme metodologia descrita pela ISO 7932:2004. A contagem de Staphylococcus aureus, foi realizada conforme metodologia descrita pela ISO 6888-1:1999. A pesquisa de Salmonella foi realizada pelo equipamento VIDAS ${ }^{\circledR}$ conforme metodologia descrita pela AOAC (2011).

\section{RESULTADOS E DISCUSSÕES}

$\mathrm{Na}$ Tabela 1, são apresentados os resultados da caracterização microbiológica do Iogurte de Leite de Ovelha.

Tabela 1 - Caracterização microbiológica do iogurte de leite de ovelha

\begin{tabular}{ccc}
\hline Caracterização Microbiológica & Contagem & Legislação \\
\hline Coliformes Totais a $30{ }^{\circ} \mathrm{C}(\mathrm{UFC} / \mathrm{g})$ & $<1,0 \times 10 \pm 1,3$ & $10^{2}$ \\
Coliformes Termotolerantes a $45^{\circ} \mathrm{C}(\mathrm{UFC} / \mathrm{g})$ & $<1,0 \times 10 \pm 1,5$ & 10 \\
Bactérias láticas $(\mathrm{UFC} / \mathrm{g})$ & $2,0 \times 10^{9} \pm 2,1$ & $>10^{7}$ \\
Bolores e leveduras $(\mathrm{UFC} / \mathrm{g})$ & $<1,0 \times 10 \pm 2,2$ & $2 \times 10^{2}$ \\
Salmonella $\mathrm{sp}($ Ausência/25 g) & Ausente & Ausente \\
\hline
\end{tabular}

Todos os resultados da caracterização microbiológica do iogurte de leite de ovelha atenderam aos requisitos preconizados pela legislação brasileira, RDC No 12 (Brasil, 2001), bem como o regulamento técnico de identidade e qualidade de leites fermentados.

$\mathrm{Na}$ Tabela 2, são apresentados os resultados da caracterização físico-química do iogurte de leite de ovelha. Pode-se verificar que o produto apresentou 83,77\% de umidade e 0,24\% de cinzas, corroborando com os dados obtidos por Mishra e Kumar (2004), que encontraram $81,9 \%$ de umidade e $0,7 \%$ de cinzas no iogurte de leite de ovelha. O teor de lactose foi de $4,59 \%$, estando próximo aos valores encontrados por Katsiari et al. (2001) e Hilali et al. (2011), que foram de 4,87\% e 4,84\%, respectivamente, no iogurte de leite de ovelha.

O iogurte de leite de ovelha apresentou 5,84\% de lipídios, classificando-se como integral, que compreende a faixa de $3 \%$ a 5,9\%, segundo a IN N 46 do MAPA (Brasil, 2007).

Tabela 2 - Caracterização físico-química do iogurte de leite de ovelha

\begin{tabular}{ccc}
\hline Caracterização & Valores & Legislação \\
\hline Umidade (\%) & $83,77 \pm 0,42$ & - \\
Lipídios (\%) & $5,84 \pm 0,52$ & 3 a 5,9 - Integral
\end{tabular}


Proteína (\%)
Lactose (\%)
Cinzas (\%)

Acidez em ácido lático $(\mathrm{g} / 100 \mathrm{~g})$
$5,56 \pm 0,55$

$4,59 \pm 0,47$

$0,24 \pm 0,65$

$1,10 \pm 0,30$
Mínimo 2,9

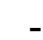

0,6 a 2

$$
\mathrm{pH} \quad 4,63 \pm 0,20
$$

O teor mínimo de proteína especificado pela legislação para o iogurte é de $2,9 \%$, assim, o teor de proteína do iogurte de leite de ovelha encontra-se dentro dos padrões especificados, corroborando com os valores encontrados por Katsiari et al. (2001) e Hilali et al. (2011) de $5,85 \%$ e $5,64 \%$, respectivamente, no de iogurte de leite de ovelha.

A acidez encontrada foi de $1,10 \mathrm{~g} / 100 \mathrm{~g}$, estando de acordo com o Regulamento Técnico de Identidade e Qualidade de Leites Fermentados, que determina uma faixa de 0,6 a $2 \mathrm{~g} / 100 \mathrm{~g}$. $\mathrm{O} \mathrm{pH}$ foi de 4,63, semelhante aos valores encontrados por Mishra e Kumar (2004) que foi de 4,60 em iogurte de leite de ovelha. ovelha.

Na Tabela 3, apresenta-se a caracterização microbiológica do iogurte em pó de leite de

Tabela 3 - Caracterização microbiológica do iogurte em pó de leite de ovelha

\begin{tabular}{cc}
\hline Caracterização Microbiológica & Contagem \\
\hline Bacillus cereus $(\mathrm{UFC} / \mathrm{g})$ & $3,7 \times 10^{2} \pm 1,2$ \\
Coliformes Termotolerantes a $45^{\circ} \mathrm{C}(\mathrm{UFC} / \mathrm{g})$ & $<1,0 \times 10 \pm 1,7$ \\
Staphylococcus aureus coagulase positiva $(\mathrm{UFC} / \mathrm{g})$ & $<1,0 \times 10 \pm 1,5$ \\
Bactérias láticas (UFC/g) & $4,0 \times 10^{7} \pm 2,5$ \\
Salmonella sp. (Ausência/25 g) & Ausente \\
\hline
\end{tabular}

Os limites estabelecidos na RDC No 12 da ANVISA (Brasil, 2002), para contagem de Bacillus cereus, Coliformes Termotolerantes a $45^{\circ} \mathrm{C}$, Staphylococcus aureus coagulase positiva e Salmonella sp são respectivamente, $5 \times 10^{3} \mathrm{UFC} / \mathrm{g}, 10 \mathrm{UFC} / \mathrm{g}, 10^{2} \mathrm{UFC} / \mathrm{g}$ e ausente. Os resultados encontrados para o iogurte em pó, conforme a Tabela 3, estão de acordo com os limites estabelecidos pela legislação.

Com a aplicação do processo de liofilização no iogurte de leite de ovelha para a produção de iogurte em pó, ocorreu uma redução de dois ciclos logarítmicos na contagem de bactérias láticas. Apesar da redução na contagem de bactérias lácticas, o produto atende aos requisitos preconizados pela $\mathrm{IN} \mathrm{N}^{\mathrm{o}} 46$ do MAPA (Brasil, 2007), que é de 4,0 x $10^{7} \mathrm{UFC} / \mathrm{g}$, para ser classificado como iogurte. ovelha.

$\mathrm{Na}$ Tabela 4, apresenta-se a caracterização físico-química do iogurte em pó de leite de 
Tabela 4 - Caracterização Físico-química do iogurte em pó de leite de ovelha

\begin{tabular}{cc}
\hline Caracterização & Valores \\
\hline Umidade (\%) & $3,29 \pm 0,54$ \\
Lipídios (\%) & $38,52 \pm 0,60$ \\
Proteína (\%) & $29,08 \pm 0,48$ \\
Lactose (\%) & $18,99 \pm 0,56$ \\
Cinzas (\%) & $5,01 \pm 0,23$ \\
Acidez em ácido lático (g/100g) & $1,40 \pm 0,20$ \\
Atividade de Água & $0,26 \pm 0,10$ \\
pH & $4,72 \pm 0,10$ \\
\hline
\end{tabular}

Conforme os dados apresentados na Tabela 4, para o iogurte em pó de leite de ovelha, a umidade encontrada foi de 3,29 \%, este resultado corrobora o de Mishra e Kumar (2004), que obtiveram $5 \%$ para o iogurte em pó de leite de ovelha, obtido pelo processo de liofilização. A atividade de água do iogurte obtido por liofilização foi de 0,26. Este valor se aproxima ao encontrado por Medeiros (2013), que foi de 0,09 a 0,19, para o iogurte em pó de leite de cabra, obtido pelo processo de spray dryer, no qual as temperaturas dos testes variam de $130{ }^{\circ} \mathrm{C}$ a $170{ }^{\circ} \mathrm{C}$.

$\mathrm{O} \mathrm{pH}$ e acidez do iogurte em pó de leite de ovelha foi de 4,72 e 1,40 g/100 g, respectivamente (Tabela 4), foram superiores aos valores iniciais do iogurte de leite de ovelha (Tabela 2). Esta variação do $\mathrm{pH}$ e acidez, embora não sejam expressivos, podem ser decorrentes de processos de decomposição, seja por hidrólise, oxidação ou fermentação (IAL, 2008).

Já o teor de proteínas, no iogurte em pó de leite de ovelha, foi de $29,08 \%$, abaixo do valor encontrado por Mishra e Kumar (2004), que obtiveram de $35 \%$ a $37 \%$ de proteínas para o mesmo produto.

\section{CONCLUSÃO}

A utilização do processo de liofilização no iogurte de leite de ovelha para transformação em iogurte em pó permitiu manter as características físico-químicas (proteína, lipídios, lactose, cinzas, acidez e pH) e microbiológicas, assim sendo classificado como iogurte, pois a contagem de bactérias lácticas atende ao estabelecido pela legislação que é maior que $10^{7} \mathrm{UFC} / \mathrm{g}$.

\section{REFERENCIAS}

ASSOCIATION OF OFFICIAL ANALYTICAL CHEMISTS - AOAC. Official methods of analysis. 17.ed. Washington: AOAC, 2002. 1115p. 
BRASIL. Ministério da Saúde. Agência Nacional de Vigilância Sanitária - ANVISA. Resolução RDC 12, de 02 de janeiro de 2001. Regulamento Técnico Sobre Padrões Microbiológicos para Alimentos. Diário Oficial da União, Brasília, DF, 10 jan. 2001. Seção 1, p. 45-53.

BRASIL. Ministério da Agricultura, Pecuária e Abastecimento. Instrução. Normativa $n^{\circ} 46$ de 23 de outubro de 2007. Regulamento Técnico de Identidade e Qualidade de Leites Fermentados. Diário Oficial da União, Brasília, 24 out. 2007, Seção 1.

BRASIL. Ministério da Agricultura, Pecuária e Abastecimento. Instrução Normativa $\mathrm{n}^{\circ}$ 62, de 29 de dezembro de 2011. Aprova o Regulamento Técnico de Produção, Identidade e Qualidade do Leite tipo A, o Regulamento Técnico de Identidade e Qualidade de Leite Cru Refrigerado, o Regulamento Técnico de Identidade e Qualidade de Leite Pasteurizado e o Regulamento Técnico da Coleta de Leite Cru Refrigerado e seu Transporte a Granel, em conformidade com os Anexos desta Instrução Normativa. Diário Oficial da República Federativa do Brasil, Brasília, 31 dez. de 2011. Seção 1, p. 6.

BRASIL. Ministério da Agricultura, Pecuária e Abastecimento. Instrução Normativa $\mathrm{n}^{\circ} 68$ de 12 de dezembro de 2006 do Diário Oficial da União, Poder Executivo, Brasília, DF, 14 de dezembro de 2006b. Seção 1, página 8. Secretaria de Defesa Agropecuária. Departamento de Inspeção de Produtos de origem Animal. Métodos Analíticos Oficiais Físico-Químicos para Controle de Leite e Produtos Lácteos.

HILALI, M. IÑIGUEZ, L.; KNAUS, W.; SCHREINER, M.; WURZINGER, M.; MAYER, H. K. Dietary supplementation with nonconventional feeds from the Middle East: Assessing the effects on physicochemical and organoleptic properties of Awassi sheep milk and yogurt. Journal of Dairy Science, v. 94, n. 12, p. 5737-5749, 2011.

INSTITUTO ADOLFO LUTZ. IAL. Métodos físico-químicos para análise de alimentos. ZENEBON, O.; PASCUET, N. S; TIGLEA, P. (Coord.). São Paulo: Instituto Adolfo Lutz, 2008. p. 1020.

KATSIARI, M. C.; VOUTSINAS, L. P.; KONDYLI, E. Manufacture of yoghurt from stored frozen sheep's milk. Food Chemistry, v. 77, n 4, p. 413-420, 2001.

MARTÍNEZ, E. J. L.; CÓRDOVA, F.; MEDINA, A. R.; BARRALES, P. O. Analysis of 20 trace and minor elements in soy and dairy yogurts by ICP-MS. Microchemical Journal, v. 102, p. 23-27, may 2012.

MEDEIROS, A. C. L. Iogurte caprino probiótico em pó: estudo do processo de secagem, da caracterização do pó e da viabilidade do probiótico. 2013. 70f. Dissertação (Mestrado em Ciências) - Faculdade de Zootecnia e Engenharia de Alimentos - Universidade de São Paulo, Pirassununga, 2013.

MISHRA, N. H.; KUMAR, P. Yoghurt power - a review of process technology, storage and utilization. Food and Bioproducts Processing, v. 82, n. C2, p. 133-142, 2004. 